\title{
Methodical Approach for Structure Optimization of Energy Sources in the Development of heat Supply Systems
}

\author{
Valery A. Stennikov', Olga A. Edeleva ${ }^{2}$ \\ Melentiev Energy Systems Institute of Siberian Branch of the Russian Academy of Sciences, \\ Lermontov str., 130, \\ Irkutsk, Russia \\ ${ }^{1}$ E-mail: sva@isem.irk.ru \\ ${ }^{2}$ E-mail:edel@isem.irk.ru
}

\begin{abstract}
The current problem of searching for the optimal structure of equipment of energy sources with a high level of technical and economic indicators is based on the construction of the redundant scheme. A description of the mathematical formulation of this problem is given, methods are proposed for solving it, based on the preliminary formation of the redundant scheme, including various options for equipment for energy sources. For the construction of redundant circuits, the methodical approach to the problem being solved is adapted on the basis of P-graphs.
\end{abstract}

Keywords: Energy source, heat supply system, critical infrastructure, redundant scheme, P-graph.

\section{Introduction}

Heat supply systems are one of the representatives of critical infrastructures [1], as the disruption of their operation entails shortage of heat energy in the household, industry sectors and can often lead to disastrous consequences. Often this can lead to mass illnesses of people, significant financial losses, and in the most severe cases - to their resettlement from cities and large-scale damage to the economy of the country [2]. The variety of external and internal factors (the vast territory of Russia, the harsh climate, severe conditions for delivery, storage of fuel, etc.) have a significant impact on the safety of heat supply, complicate the search for effective directions for the development of heat supply systems and predetermine the need for the development of modern methodological support and computing tools for their solution. The problem of choosing the optimal structure of equipment and the most advantageous composition of energy sources in the heat supply systems of cities is a complex problem that has a nonlinear character and is difficult to formalize for practical implementation. To solve the problem is to determine the structure and location of energy sources taking into account a set of technical and economic conditions, environmental and territorial restrictions on their location. There are many publications devoted to the solution of the problems of energy sources structure optimization. [3]. Methods for opti- mizing design and verification calculations that allow calculating the heat patterns of energy sources in detail, optimizing the parameters of the operation of the main and auxiliary equipment, its operating modes are described in the publication [4]. Within the framework of the approach described in it, an original technique is proposed [5], which allows selecting the optimal number of installed generating units, power transmission lines and other network elements, taking into account normal and post-emergency operation of the power system. This methodological approach is a fairly detailed calculation and is oriented to the application in the specific design of systems and installations. Widespread use in planning problems has found aggregated approaches that allow us to consider the main directions of development of the fuel and energy complex (FEC) of the region or its branches [6-8]. The methodical tool developed on their basis [8-10] allows to forecast energy balances, perform an integrated calculation of the structure of energy sources according to their types, determine the directions of development of the fuel and energy complex in the region and its individual branches, including the electric power and heat supply industries, and form priority projects. All these approaches focus on specific tasks with their peculiarities and conditions, characteristic either for designing an energy source or for managing the development of the fuel and energy complex. To solve the problems of heat supply systems optimization at the 
level of development of the Master Plan of the city, and then the Heat Supply Scheme, performed with a significant temporal lead (15-20 years), its specialized tools are required.

The most adequate for these tasks is the methodical approach based on the construction of redundant scheme, developed both in Russia and abroad [11, 12].

In Russia, the methodical approach to the construction of redundant scheme is based on the construction of an excess design scheme of the heat supply system by the researcher, as a set of all permissible configurations of the heat network and the location of heat sources, taking into account restrictions related to barriers on the ground and selected for source placement by sites [13]. The method is that when choosing sources of heat, the redundant scheme is supplemented with a fictitious node and a subset of fictitious links connecting it to those nodes in which the optimal source power is selected. The number of fictitious links for each source node depends on how many alternatives by source types in a given node are considered. The directional search of trees is carried out by local optimization of different trees of the initial approximation, which makes it possible to obtain solutions close to optimal ones. When preparing the redundant scheme, all possible alternative variants are included, thereby eliminating the risk that the optimal solution can be excluded from the examination.

Abroad, such an approach was proposed for the optimal synthesis of systems based on a superstructure similar to the redundant scheme $[14,15]$. According to this approach, various variants of the composition of equipment of energy sources are considered in a single scheme, which contains a finite number of elements with their possible interrelationships.

Well-known in the foreign practice of creating and managing systems is the methodology of power nodes [16], which is widely used in modeling integrated energy supply systems. In many respects it is identical to the methodological approach of P-graphs, the only difference being that here the method of transforming one type of energy into another is described by means of matrices and vectors. The variability of this methodology can be the transformation of the unification of energy nodes into a superstructure [17].

\section{The mathematical statement of the problem}

The task of finding the optimal equipment and structure of energy sources involves the selection of such capacities, locations and types of sources, as well as their equipment, in which the reduced costs for the system are turned into a minimum (taking into account the reduction of options to the same energy effect).

With the relative simplicity of meaningful formulation, the problems of optimizing the structure of energy sources have a large dimension, a complex system of constraints, and present a difficult object for the application of mathematical methods, especially when it comes to their computational and practical effectiveness. At the same time, these tasks are of great technical and economic importance, since they determine not only the structure of systems, their type, scales but also largely determine their parameters.

The mathematical formulation of the problem includes the objective function in the form of expression (1), a system of conditions and constraints in the form of equalities, inequalities, and logical conditions (2)(11). Set of sources $I$ of in the city consist of subsets of $U$ existing and $Z$ new energy sources. For each energy source $M_{i}$ is formed, each element of which $m$ describes a variant of reconstruction and/or modernization of the existing energy source, or installation of a new energy source.

The objective function is the sum of costs determined by the composition and productivity of the system elements, USD:

$$
\begin{aligned}
& \mathrm{S}=\sum_{i}^{I} s_{i} \cdot Q_{i}-S_{\text {out }}^{e p s} \cdot W_{\text {out }}^{\text {eps }}+ \\
& +S_{\text {in }}^{e p s} \cdot W_{\text {in }}^{\text {eps }} \Rightarrow \mathrm{min},
\end{aligned}
$$

Under the following restrictions: Balance of annual heat consumption of the city, Gcal:

$$
\sum_{i} Q_{i}=\mathrm{Q}^{\text {city }}
$$

Electricity balance, MWh:

$$
\sum_{i} W_{i}-W^{\text {city }}-W_{\text {out }}^{\text {eps }}+W_{\text {in }}^{\text {eps }}=0
$$

The condition of competition in options for the reconstruction and/or modernization of the existing energy source $i \in U$ :

$$
\sum_{m=1}^{M_{i}} V_{i}^{m}=1,
$$

The competition condition in the options for each new energy source $i \in Z$ :

$$
\sum_{m=1}^{M_{i}} V_{i}^{m}=G_{i},
$$

where $V_{i}^{m}$ is a set of equipment for an energy source $i$, option $m \in M_{i}$, which has a certain set of technical and economic characteristics. 
Generation of heat from an energy source $i$, Gcal:

$$
Q_{i}=\sum_{m}^{M_{i}} Q_{i}^{\mathrm{m}} \cdot V_{i}^{m},
$$

Power generation from an energy source $i$, MWh:

$$
W_{i}=\sum_{m}^{M_{i}} W_{i}^{m} \cdot V_{i}^{m},
$$

Dependence of the generation of heat energy on the type of fuel:

$$
Q_{i}^{m}=f\left(B_{i}^{m, h}, \ldots, B_{i}^{m+1, h+1}\right),
$$

The dependence of the electrical power on the thermal power should not be below a given level:

$$
N_{i}^{m}=f\left(Q_{i}^{m}\right)
$$

Dependence of power generation on power:

$$
W_{i}^{m}=f\left(N_{i}^{m}\right) \text {, }
$$

Limit on the amount of fuel used:

$$
B_{i}^{m, h} \leq B_{i, \max }^{m, h}
$$

where $i$ is the energy source from the set $I ; h$ is the type of burned fuel; $m$ is the number of the variant for the type and composition equipment of the energy source; $Q^{\text {city }}$ is the annual heat consumption of the city, Gcal; $W^{\text {city }}$ is the annual electricity consumption of the city, MWh; $W^{\text {eps }}$ is the the need for electricity in the electric power system, which can be covered by electricity supply from CHP, MWh; $B_{i}^{m, h}$ is the annual fuel consumption of the type $h$, it is burned by the source $i$ when the option $m$ is implemented, $B_{i}^{m, h}, \ldots, B_{i}^{m+1, h+1} ; B_{\max }^{m, h}$ is the maximum possible volume of burned fuel per year. $W_{i}$ is the electricity supply from the source $i$, MWh; $Q_{i}$ is the heat production from the source $i$, Gcal; $Q_{i}^{m}$ is the heat generation from the source $i$ when the option is implemented, Gcal; $W_{i}^{m}$ is the generation of electricity from the source $i$ when the option $m$ is implemented, MWh; $N_{i}^{m}$ is the electric power of the source $i$ when the option $m$ is implemented, MW; $V_{i}^{m}$ is the implementation of the option $m$ of reconstruction and/or expansion and/or modernization of the source $i$ or installation of a new source $i ; G_{i}$ - auxiliary variable of Boolean type, if new source is not installed, then $G_{i}=0$, if it is installed, then $G_{i}=1 . G_{i}$ depends on $V_{i}^{m}$, for example, if $V_{i}^{m}=1, G_{i}$ becomes automatically $G_{i}=1 ; S$ is the cost in the heat supply system of the city, USD; $S_{i}$ is the unit cost in the source $i$, $\mathrm{USD} / \mathrm{Gcal}$ (USD/kW); $W_{i n}^{e p s}$ is the volume of electricity which is purchased from the electricity system, MW; $W_{\text {out }}^{\text {eps }}$ is the volume of electricity which is sold to the power system, MW; $S_{i n}^{e l}$ is the tariff for the purchase of electricity by the electricity system, USD/kW; $S_{\text {out }}^{\text {el }}$ is the tariff for the sale of electricity to the electricity system, USD/kW.

Fig. 1 presents a graphical interpretation of a variety of options for the structure of energy sources of the city's heat supply systems in the form of a redundant scheme.

Rectangles $V_{i}^{m}$ indicate the number of options $m$ for the composition of equipment of the $i$ energy source. The lines form the sum of the heat in the city at the point $Q^{\text {city }}$ is the graphical reflection of the equation (2), and lines $W^{\text {city }}$ and $W^{\text {eps }}$ correspond to the coupling equation (3). Dotted lines in the fig. 1 show the possible competing options for each energy source.

The above mathematical formulation (1)-(11) is a linear programming problem with Boolean variables.

\section{The algorithm for choosing the optimal structure of energy sources}

The representation of the solution scheme of the problem in the form of a computational algorithm allows us

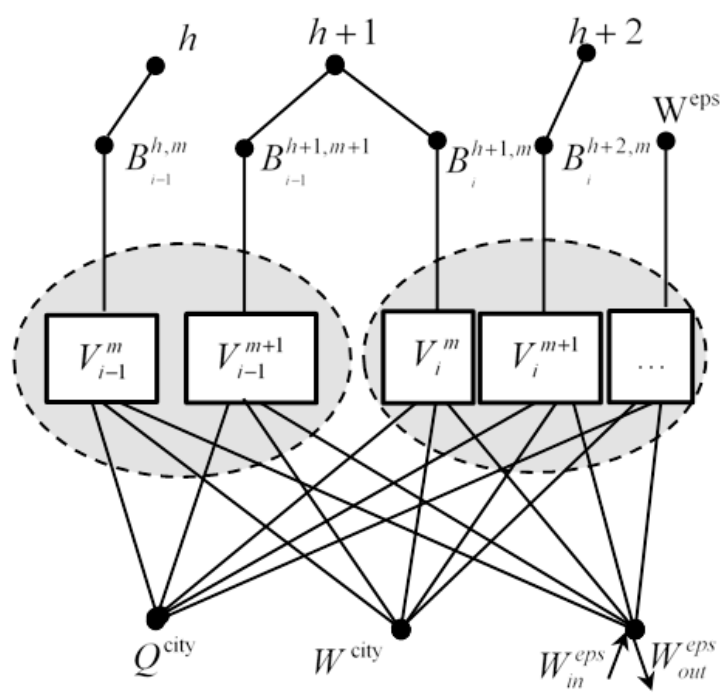

Fig. 1. Redundant scheme of the heat supply systems energy sources structure in the city.

to formalize the process of the choice of heat supply systems energy sources structure. Its graphical visualization can be depicted in the form of a diagram, shown in Fig. 2. Its visualization can be depicted in the form of the scheme (Fig. 2).

The sequence of actions of the algorithm of the choice of the optimal structure of the energy sources (Fig. 2) consists of the following logical and computational operations:

(a) Form a set of equipment types, for which it is necessary to consider all possible options for the structure of energy sources. 
(b) Construct a redundant scheme of the structure of energy sources, as shown in Fig. 2.

(c) Solve the problem (1)-(11).

(d) Go to step (e) if the solution is obtained, go to step (a), if it isn't.

(e) Preserve the calculated options of energy sources structure, return to step (b) with the modified input data. For example, a new load distribution between sources, a new territorial arrangement of energy sources, etc.

(f) Select and analyze the optimal version of the structure of energy sources.

\section{Methodical approach to modeling redundant schemes of energy source structures based on P- graphs}

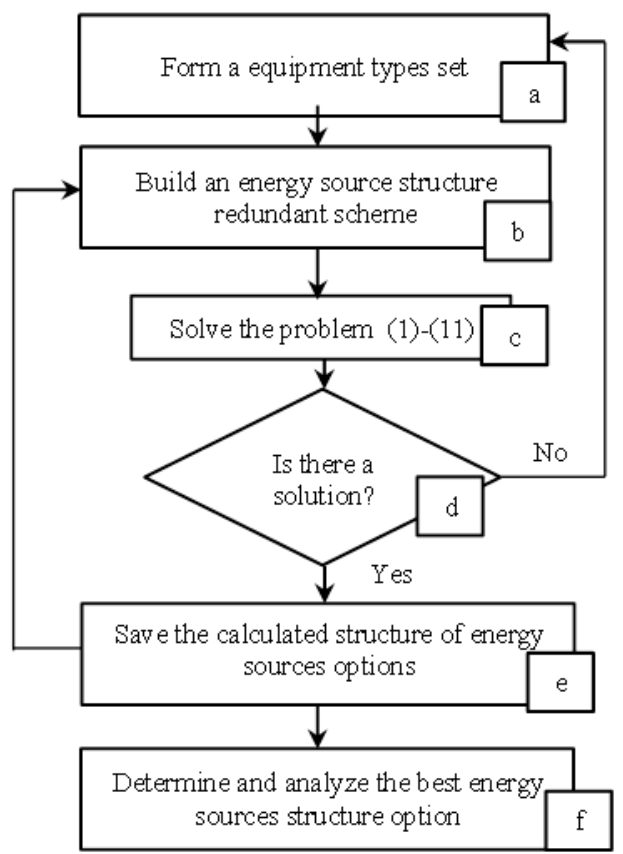

Fig. 2. The algorithm to choose the optimal structure of the city energy sources.

Modeling of redundant scheme uses the methodic approach based on P-graphs, it is a graphical model of energy conversion processes, including [14, 15]:

(i) A set of energy carriers (fuel, heat energy, electricity, etc.);

(ii) A set of equipment (main and auxiliary equipment of energy sources with corresponding technical and economic indicators);

(iii) A set of available technological units. The technological unit is a set of pairs of elements from points 1 and 2 and is a converter of energy carriers (boiler, gas compressor unit, turbine, consumer inputs, etc.).
The technological unit produces output energy carriers, provided that all input energy carriers are available. The technological block has both structural and parametric properties. Thus, the input energy carriers are consumed, and the output energy carriers are produced in accordance with the unit costs specified in the arcs that enter or exit from the corresponding technological block. Input and output energy carriers, the above-mentioned unit costs and the total cost function together form a technological unit.

The obtained mathematical model contains noncontinuous and binary variables for each technological block. The first determines the power of the unit, the latter determines whether the unit can be installed or operated. The mathematical model ensures the observance of the mass balance in any material node, i.e. the sum of the outgoing streams is equal to the sum of the incoming flows. Another limitation ensures that if the technology block is not included in the solution, then the corresponding power variable will be zero. The mathematical model is able to determine several best optimal solutions.

In the whole, methodical approach P-graphs allows solving the problem (1)-(11) of graph theory. Specialized algorithms are developed on the P-graphs: MSG for generating maximum structures [18, 19], SSG for generations of cone structure [18, 20], ABB has determined optimal structures [21]. The algorithms are available in P-Graph Studio [22].

\section{The practical design of the redundancy scheme of the energy source structure based on the P-graph}

The creation of a redundant scheme of an energy source begins with the selection of options for the composition of equipment. The choice of the optimal structure is made for the excess composition of equipment of a single energy source, it has the added heat, which load is $1.32 \mathrm{Gcal} / \mathrm{h}$. Technical, economic and cost indicators for options of energy source equipment are given in Table 1.

In the first option, it is proposed to install boilers E1/9-1M for oil liquid fuel, the second option suggests the installation Mini-CHP based on gas units SITA54 of French production of low power on the gas fuel, in the third option, it is installed Mini-CHP based on gas units ДГ $98 \mathrm{M}$ with a waste heat boiler КУВ-30 of low power on gas fuel.

The options are given to an equal energy effect of heat and electricity. For this, in the case when the energy source equipment does not produce electricity, it is 
purchased from the external electric power system (Table 1 , the option no. 1).

Table 1. Power plant options for one energy source, the added heat load is $1.32 \mathrm{Gcal} / \mathrm{h}$

\begin{tabular}{l|c|c|c}
\multicolumn{1}{c|}{ Parameter name } & \multicolumn{3}{c}{ Value } \\
\hline Option number & 1 & 2 & 3 \\
\hline Power plant type & E-1/9-1M & $\begin{array}{c}3516 \mathrm{HR} \\
\text { SITA54 }\end{array}$ & $\begin{array}{c}\text { ДГ98M- } \\
\text { KУB-30 }\end{array}$ \\
\hline Power plants number & 3 & 2 & 2 \\
\hline Fuel type & $\begin{array}{c}\text { oil liquid } \\
\text { fuel }\end{array}$ & gas & gas \\
\hline $\begin{array}{l}\text { The consumption of } \\
\text { conventional fuel by one } \\
\text { power plant, kgce/h }\end{array}$ & 81.4 & 464.7 & 471.2 \\
\hline $\begin{array}{l}\text { Annual costs for the } \\
\text { purchase of fuel by one } \\
\text { power plant, USD/year }\end{array}$ & 152280 & 124837 & 125675 \\
\hline Heat energy, Gcal/h & 1.965 & 1.64 & 1.34 \\
\hline $\begin{array}{l}\text { Electrical power of one } \\
\text { power plant, MW }\end{array}$ & - & 1.03 & 1 \\
\hline Electricity import, MW & 2 & - & - \\
\hline $\begin{array}{l}\text { Annual costs of electric- } \\
\text { ity purchase, USD/year }\end{array}$ & 720000 & - & - \\
\hline $\begin{array}{l}\text { The cost of a set of } \\
\text { power plants, thousand }\end{array}$ & 20.1 & 11 & 12 \\
$\begin{array}{l}\text { USD } \\
\text { InS }\end{array}$ & & &
\end{tabular}

Fig. 3 shows the block diagrams of the power plants (it is created according to the data of Table 1). The option of the equipment composition of the energy source and their image is realized in P-graphs.

Fig. 4 shows the redundant scheme of the structure of the energy source, it is built in the P-studio system, the dotted lines show competing options for the com-
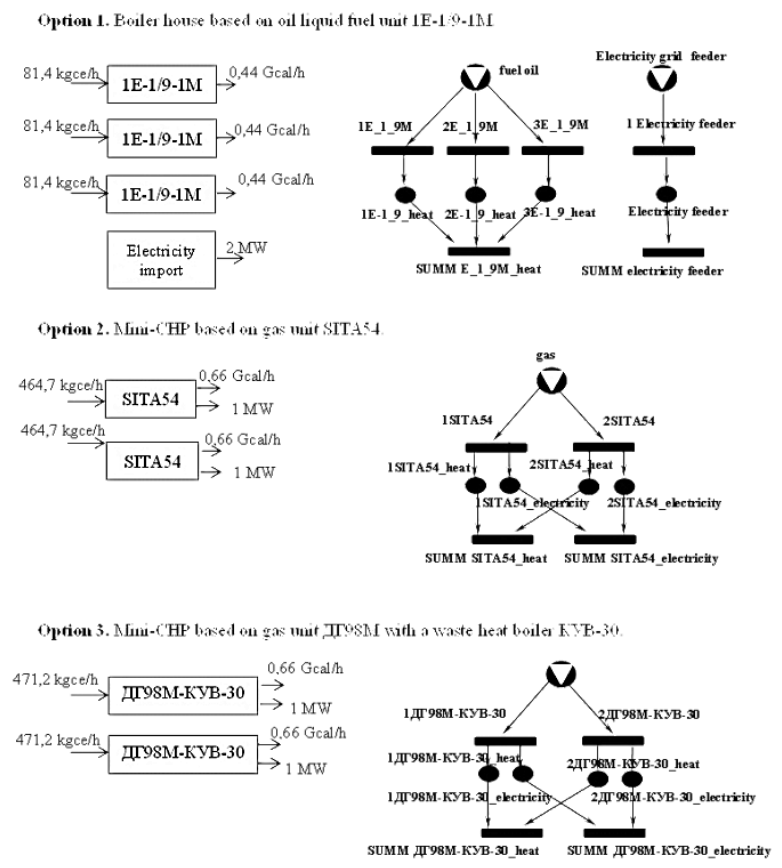

Fig. 3. The construction of P-graph elements according to the options of power plants block diagrams. position of equipment for the energy source.

Fig. 5 shows the choice of the optimal equipment for the energy source, this is option 2 with a $3512 \mathrm{HR}$ SITA54 unit on the natural gas.

This calculation uses given variants, although the

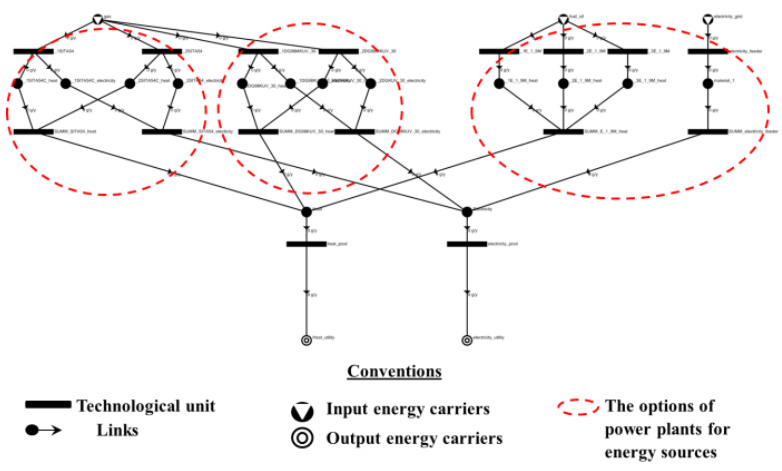

Fig. 4. Building redundant scheme of energy sources equipment.

methodological approach allows generating variants and creates a superstructure automatically, there are many examples of such algorithms for automatic gen-

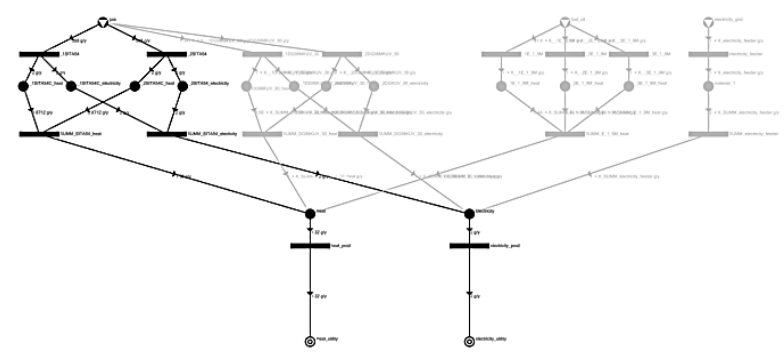

Fig. 5. Choice the best energy source structure option.

eration of superstructures, for example, in [27, 28] the authors use the PNS approach (process network synthesis).

\section{Conclusions}

A brief review of the existing methodological approaches to optimizing the structure of heat supply system energy sources was made. Based on this, the main advantages of using redundant scheme were formulated and directions for further research were outlined.

A mathematical formulation of the problem of the energy sources optimal structure is given, in which the competition of energy source options is described in explicit form, as well as the methodology of redundant design schemes. To graphically illustrate the proposed mathematical formulation of the problem, a scheme is given for the formation of a redundant structure of energy sources. 
A brief description of the methodological approach to the construction of redundant schemes of structures is given. It is based on P-graphs and uses methods of graph theory.

A practical example of choosing the structure of equipment for a single energy source is realized. It shows the successful adaptation of the theory of Pgraphs to the problem being solved.

\section{Acknowledgements}

The work was carried out within the framework of scientific project III.17.4.3., the program of fundamental research of the SB RAS no. AAAA-A17117030310437-4.

\section{References}

1. Council Directive 2008/114/EC of 8 December 2008 on the identification and designation of European critical infrastructures and the assessment of the need to improve their protection, Official Journal of the European Union, L 345 (2008) 75-82. [Online]. Available: http://eurlex.europa.eu/LexUriServ/LexUriServ.do?uri=O J:L:2008:345:0075:0082:EN:PDF, Accessed on Apr. 26, 2018.

2. Federal Law of 21.07.2011 No. 256 On the safety of objects of the fuel and energy complex. 23 p. [Online]. Available: http://www.kremlin.ru/acts/bank/33689/page/1 Accessed on: Apr. 26, 2018. [In Russian].

3. O.A. Edeleva, Choice of the methodical approach for solving problems of optimal development of energy sources in the heat supply systems of urban areas, $J$. Izvestiya Vysshikh Uchebnykh Zavedenii. Problems of energy, no. 5-6 (2017) 56-68. [In Russian].

4. A.M. Kler, E.L. Stepanova, A.S. Maksimov et al., Optimization of the operating modes of the CHP taking into account the real state of the main equipment, J. Teploenergetika no. 6 (2009) 53-57. [In Russian].

5. A.M. Kler, P.V. Zharkov, Development of methods for optimizing schemes and parameters of local electric power systems, in Sb. articles of the all-Russian conference "Energy of Russia in the XXI century. Innovative development and management (Melentiev Energy Systems Institute SB RAS, Russia, Irkutsk, 2015), pp. 568-577. [In Russian].

6. B.G. Saneev, A.D. Sokolov, G.V. Agafonov et al., Methods and models for the development of regional energy programs (Nauka, Russia, Novosibirsk, 2003).

7. L.S. Belyaev, B.G. Saneev, S.P. Filippov . et al, N.I. Voropay (eds.), System studies of energy problems (Science. Siberian Publishing Company of RAS, Russia, Novosibirsk, 2000). [In Russian].

8. B.M. Kaganovich, S.P. Filippov, E.G. Antsiferov, The efficiency of energy technologies: thermodynamics, economics, forecasts (Nauka, Russia, Novosibirsk, 1989). [In Russian].

9. N.I. Pyatkova, V.I. Rabchuk, S.M. Senderov et al, N.I. Voropay and M.B. Cheltsov (eds.), The energy security of Russia: problems and solutions (Melentiev Energy Systems Institute SB RAS, Russia, Novosibirsk, 2011). [In Russian].

10. E. Vander Voort, E. Donni, C. Thonet, E. Bois D'Enghien, G. Dechamps, J.F. Guilmot, Energy supply modelling package EFOM-12C Mark I: mathematical description (Louvain-La-Neuve, Belgium, Cabay, 1984).

11. N.N. Merenkova, E.V. Sennova, V.A. Stennikov, Scheme-structural optimization of centralized heat supply systems, J. Elektronnoe modelirovanie, no. 6 (1982) $76-82$

12. S. Mitra, L. Sun, I.E. Grossmann, Optimal scheduling of industrial combined heat and power plants under timesensitive electricity prices, J. Energy, 54 (2013) 194-211. [In Russian].

13. E.V. Sennova, V.G. Sidler, The mathematical modeling and optimization of the developing heat supply systems, (Nauka, Russia, Novosibirsk, 1987).

14. H. L. Lam, Extended P-graph applications in supply chain and process network synthesis, J. Current Opinion in Chemical Engineering, 2(4) (2013) 475-486. 
15. F. Friedler, K. Tarjan, Y. W. Huang, L. T. Fan, Graphtheoretic approach to process synthesis: axioms and theorems, J. Chemical Engineering Science, 47(8) (1992), pp. 1973-1988.

16. M. Giedl, G. Andersson, Optimal Coupling of Energy Infrastructures. J. Power Tech, IEEE Lausanne (2007) 1398-1403.

17. M. Almassalkhi, I. Hiskens, Optimization framework for the analysis of large scale networks of energy hubs, in 17th Power System Computation. Conf. (Sweden, Stockholm, 2011), 7p.

18. F. Friedler, K. Tarjan, Y. Huang and L. Fan, Combinatorial algorithms for process synthesis. J. Comput. Chem. Eng. 16(Supplement 1) (1992) 313-320.

19. F. Friedler, K. Tarjan, Y. Huang and L. Fan, Graphtheoretic approach to process synthesis: Polynomial algorithm for maximal structure generation. J. Comput. Chem. Eng. 17(9) (1993) 929-942.

20. F. Friedler, J.B. Varga, L.T. Fan, Decision-mapping: a tool for consistent and complete decisions in process synthesis, J. Chemical Engineering Science, 50(11) (1995) $1755-1768$.

21. F. Friedler, J. B.Varga, E. Feher, L. T. Fan, Combinatorially accelerated branch-and-bound method for solving the MIP model of process network synthesis, State of the Art in Global Optimization (Springer US, 1996), pp. 609626.

22. Algorithms. MSG Algorithm, SSG Algorithm, ABB Algorithm. [Online]. Available: http://p-graph.com/, Accessed on: March 8, 2018.

23. N. Voropai, V. Stennikov, S. Senderov, E. Barakhtenko, O. Voitov and A. Ustinov, Modeling of Integrated Energy Supply Systems: Main Principles, Model, and Applications. Journal of Energy Engineering, 143(5) (2017) $1-11$.

24. N.I. Voropai, V.A. Stennikov, E.A. Barakhtenko, Integrated energy systems as an innovative direction of the energy future, in Sb. articles of the all-Russian conference "Energy of Russia in the XXI century. Innovative development and management (Melentiev Energy Systems Institute SB RAS, Russia, Irkutsk, 2015), pp. 47-55. [In Russian].

25. M. C. Bozchalui, S. A. Hashmi, H. Hassen, C. A. Canizares, K. Bhattacharya, Optimal Operation of Residential Energy Hubs in Smart Grids, Smart Grid. J. IEEE Transactions on, 3 (2012) 1755-1766.

26. J. Chunlian, L. Shuai, L. Ning, and R. A. Dougal, Crossmarket optimization for hybrid energy storage systems, $J$. Power and Energy Society General Meeting. IEEE, (2011) 1-6.

27. R. R. Tan, C. D. Cayamanda, K. B. Aviso, P-graph approach to optimal operational adjustment in polygeneration plants under conditions of process inoperability, $J$. Applied Energy, 135 (2014) 402-406.

28. Raymond R. Tan, Kathleen B. Aviso, Krista Danielle S. Yu, Michael Angelo B. Promentilla, Joost R. Santos, PGraph Approach to Allocation of Inoperability in Urban Infrastructure Systems, J. Chemical Engineering Transactions, 45 (2015) 1339-1344. 